\title{
Synchrotron radiation XRPD study on the early hydration of cements
}

M. Merlini ${ }^{1,2, *}$, C. Meneghini ${ }^{3,2}$, G. Artioli ${ }^{1}$, T. Cerulli ${ }^{4}$

${ }^{1}$ Dipartimento di Scienze della Terra “Ardito Desio", Università degli Studi di Milano, Via Botticelli, 23, I-20133 Milano, Italy

${ }^{2}$ CNR-OGG, clo ESRF, GILDA CRG, BP220 F-38043 Grenoble, France

${ }^{3}$ Dipartimento di Fisica "E. Amaldi", Università di RomaTre, Via della Vasca Navale, Roma

${ }^{4}$ Mapei S.p.A, Lab. Ricerca e sviluppo, Via Cafiero 22, I-20158 Milano, Italy

*Contact author; e-mail: marco.merlini@unimi.it

Keywords: cement, hydration, powder diffraction, synchrotron radiation

\begin{abstract}
Synchrotron radiation X-ray powder diffraction has been used to monitor the evolution of hydrous phases during the first hours of the hydration process on synthetic clinker phases and on commercial cements. In order to collect data as soon as water is added to the system, the hydration of the paste was achieved using a remote controlled system. The data were quantitatively analysed via full-profile Rietveld method. The results of quantitative analysis (phase composition) and the lattice parameters determination are very useful to obtain detailed information on the structural evolution of the hydrous phases, in particular during the early stages of the hydration processes.
\end{abstract}

\section{Introduction}

Cements and concrete are among the widest widespread materials for building and their history goes back at least to the Romans. Nevertheless the details of the hydration process of cements are still not completely clarified, even if the cement chemistry is well known in its most important features [1-3]. We performed in-situ XRPD (x-ray powder diffraction) experiments during the first hours of hydration of commercial Portland Cements (PC) and synthetic clinker phases. The aim of such experiments was to use XRPD techniques to identify, characterize and quantify the crystalline phases present during the hydration of cements. The main crystalline phases of PC are $\mathrm{Ca}_{3} \mathrm{SiO}_{5}-\mathrm{C} 3 \mathrm{~S}$ - (about $60 \%$ by weight), $\mathrm{Ca}_{2} \mathrm{SiO}_{4}-$ $\mathrm{C} 2 \mathrm{~S}-(20 \%), \mathrm{Ca}_{3} \mathrm{Al}_{2} \mathrm{O}_{6}-\mathrm{C} 3 \mathrm{~A}-(10 \%)$ and $\mathrm{Ca}_{2} \mathrm{AlFeO}_{5}-\mathrm{C} 4 \mathrm{AF}(10 \%)$. Tricalcium aluminate, $(\mathrm{C} 3 \mathrm{~A})$ plays a fundamental role in the early stages of hydration process of $\mathrm{PC}$ [1]. The reaction of $\mathrm{C} 3 \mathrm{~A}$ with water produces calcium aluminate hydrates, Afm-type phases according to the cement nomenclature, and the more thermodynamically stable hydrogarnet $\mathrm{Ca}_{3} \mathrm{Al}_{2}(\mathrm{OH})_{12}-\mathrm{C} 3 \mathrm{AH} 6[1,2]$. The hydration of $\mathrm{C} 4 \mathrm{AF}$ gives similar hydrous phases, Afm and hydrogarnet. The hydration of $\mathrm{C} 3 \mathrm{~A}$ is a strongly exothermic reaction and if the kinetics is not controlled, the so-called "flash-setting" of cement may occur with undesirable effect on the rheological properties of the hydrating paste [1]. In order to prevent this reaction in ce- 
ments, Ca-sulphate is usually added to the clinker [3]. When sulphates are present, ettringite, $\left(\mathrm{C} 3 \mathrm{~A} .3 \mathrm{CaSO}_{4} .32 \mathrm{H}_{2} \mathrm{O}\right)$ is the phase that crystallises during the hydration of $\mathrm{C} 3 \mathrm{~A}$ and the reaction is less exothermic. XRPD analyses show that crystalline ettringite is present since the early stages of hydration of the C3A paste. During the hydration of PC ettringite forms as soon as water is added to the system. Ettringite is the only crystalline hydrate phase in the first 3-4 hours. After the set of cement is finished, C-S-H (Ca-Si-Hydrate) and $\mathrm{Ca}(\mathrm{OH})_{2}$ form. When Ca-sulphate is no more available in the system, ettringite starts to react with the unreacted $\mathrm{C} 3 \mathrm{~A}$ and $\mathrm{C} 4 \mathrm{AF}$ to produce monosulphate, $3 \mathrm{C} 3 \mathrm{~A}^{-\mathrm{CaSO}_{4}} \cdot 14 \mathrm{H}_{2} \mathrm{O}$. The chemical reactions occurring during the hydration process of pure clinker phases and of cements are here summarised:

$$
\begin{aligned}
& \mathrm{C} 3 \mathrm{~A}+\mathrm{H}_{2} \mathrm{O}^{\text {(excess) }} \rightarrow \mathrm{C} 3 \mathrm{Ann} \mathrm{H}_{2} \mathrm{O}(\mathrm{Afm}) \\
& \mathrm{C} 3 \mathrm{AnnH} \mathrm{H}_{2} \mathrm{O}(\mathrm{Afm}) \rightarrow \mathrm{C} 3 \mathrm{AH} 6+\mathrm{H}_{2} \mathrm{O} \\
& \mathrm{C} 3 \mathrm{~A}+\mathrm{CaSO} 4 \times \mathrm{xH}_{2} \mathrm{O}+\mathrm{H} 2 \mathrm{O}^{\text {(excess) }} \rightarrow \mathrm{C} 3 \mathrm{~A} \cdot 3 \mathrm{CaSO}_{4} \cdot 32 \mathrm{H}_{2} \mathrm{O} \\
& \mathrm{C} 3 \mathrm{~S}+\mathrm{H}_{2} \mathrm{O}^{\text {exc }} \rightarrow \mathrm{C}_{\mathrm{x}} \mathrm{S} \mathrm{H} \mathrm{H}_{\mathrm{y}}+(3-\mathrm{x}) \mathrm{Ca}(\mathrm{OH})_{2} \\
& \mathrm{C} 3 \mathrm{~A} 3 \mathrm{CaSO}_{4} \cdot 32 \mathrm{H}_{2} \mathrm{O}+2 \mathrm{C} 3 \mathrm{~A}+\mathrm{H}_{2} \mathrm{O}^{\text {exc }} \rightarrow 3 \mathrm{C} 3 \mathrm{ACaSO}_{4} \cdot 14 \mathrm{H}_{2} \mathrm{O}
\end{aligned}
$$

Reactions (1) and (2) occur when Ca sulphate is not present in the system. Reaction (5) occurs when all $\mathrm{Ca}$ sulphate has reacted.

\section{Experimental}

We performed in-situ X-Ray Powder diffraction experiments during the hydration of pure synthetic $\mathrm{C} 3 \mathrm{~A}\left(\mathrm{Ca}_{3} \mathrm{Al}_{2} \mathrm{O}_{6}\right)$ and $\mathrm{C} 4 \mathrm{AF}\left(\mathrm{Ca}_{2} \mathrm{AlFeO}_{5}\right)$ and commercial 52.5 class Portland $\mathrm{Ce}-$ ment $(\mathrm{PC})$. $\mathrm{C} 3 \mathrm{~A}$ and $\mathrm{C} 4 \mathrm{AF}$ were prepared by mixing in the stoichiometric ratio pure reagent grade $\mathrm{Al}_{2} \mathrm{O}_{3}, \mathrm{Fe}_{2} \mathrm{O}_{3}$ and $\mathrm{CaCO}_{3}$. The mixtures were heated 4 hours in air at $1000{ }^{\circ} \mathrm{C}$, then crushed, mixed, pelletised and heated 12 hours in air at $1450{ }^{\circ} \mathrm{C}$ with intermediate grindings. The products synthesised were analysed by laboratory X-ray powder diffraction and almost pure cubic $\mathrm{C} 3 \mathrm{~A}$ and $\mathrm{C} 4 \mathrm{AF}$ were detected. It was ground and sieved; for the hydration experiments the fraction smaller than $63 \mu \mathrm{m}$ was used. In some experiments Ca-sulphate hemihydrate $\left(\mathrm{CaSO}_{4} \cdot 0.5 \mathrm{H}_{2} \mathrm{O}\right)$, obtained by the dehydration of gypsum was added. The X-ray powder diffraction experiments were performed at the European Synchrotron Radiation Facility (ESRF), Grenoble at the beam lines BM16 (now transferred to ID31) and BM08 (GILDA). In the experiments carried out at BM16 the wavelength used was $0.35448 \AA$, calibrated against standard silicon NIST SRM 630b. The samples were contained in a $1 \mathrm{~mm}$ glass capillary and water or solutions containing additives were injected in the capillary by a remote controlled peristaltic pump. The X-ray beam dimension at the sample was approximately $1(\mathrm{v}) \times 2(\mathrm{~h}) \mathrm{mm}^{2}$. Powder diffraction patterns were collected in the angular range 0.5 $15^{\circ} 2 \Theta$, corresponding to a d-spacing range of 20.0-0.70 $\AA$. Each experiment lasted few hours and in order to achieve an appropriate compromise between counting statistics and time-resolution, the scan speed was decreased during the experiment from 1 to $0.2^{\circ} 2 \Theta / \mathrm{min}$. The experiments performed at the GILDA beamline, were isothermal runs at $25^{\circ} \mathrm{C}$ and also at higher temperatures, to speed up the reactions. The samples were heated with a hot gas blower and the powder patterns were collected with a translating image plate (TIP) system detector [4]. This experimental set-up, designed for time resolved XRPD experiments with time resolution in the minute range, is particularly suited for studying our reaction kinetics during early stages of hydration process. The wavelength used was $0.68888 \AA$ calibrated 
against standard LaB6, NIST SRM 660c. The isothermal runs lasted 4 hours and the timeresolution was 2 minutes. The angular range explored was $1-40{ }^{\circ} 2 \Theta$, corresponding to a dspacing interval 19-1 $\AA$. All the powder diffraction patterns were indexed and elaborated with the Rietveld method using the GSAS software [5]. The Rietveld refinements were performed using structural models for the phases taken from the ICSD - Inorganic Crystal Structure Database (C3A: ICSD\#1841; C4AF: ICSD\#9197; C2S: ICSD\#39110; C3S: ICSD\#64759). The refined parameters were: the scale factors, 15 terms for the background, modelled with a Chebyschev polynomial, the lattice parameters, and the profile parameters, in particular two coefficients for the Lorentian contribution to the full width at half maximum (FWHM) of the diffraction peaks for the data collected at BM16 and also a Gaussian term for the pattern collected at BM08. The profile function used was a pseudo-Voigt. The residual parameter wRp was in the range of $5-10 \%$ for all the patterns analysed.

\section{The hydration of $\mathrm{C} 3 \mathrm{~A}$ and $\mathrm{C} 4 \mathrm{AF}$}

The Afm type [1] phases formed during the hydration of $\mathrm{C} 3 \mathrm{~A}$ and $\mathrm{C} 4 \mathrm{AF}$ have a layered structure and water molecules can be allocated between layers. The stability of the highest hydrate phase is restricted to low temperature $\left(<30^{\circ} \mathrm{C}\right)$ [1], and high humidity. Figure 1 shows some XRPD patterns related to the hydration of C3A, and in Figure 2 the results of Rietveld analysis are reported.

\section{counts/s}

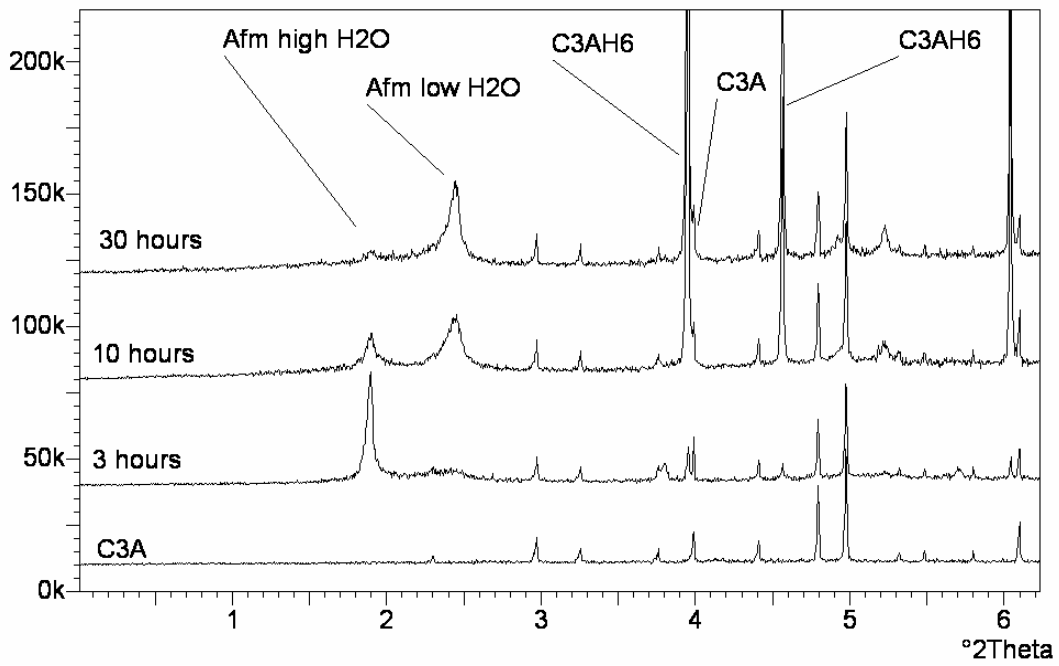

Figure 1. XRPD pattern related to the hydration of C3A.

The model used for Afm phase in Rietveld refinements is a hexagonal structure derived by the model of Taylor [1] $\left(a=5.76 \AA, c=64.14 \AA\right.$, space group $\left.\mathrm{P}_{3}\right)$. The structure of the layers can be derived from the portlandite $-\mathrm{Ca}(\mathrm{OH})_{2}$ - structure (hexagonal packing of $\mathrm{Ca}$ ions, each one coordinated by six $\mathrm{OH}$ ), with the substitution of half $\mathrm{Ca}$ ions with $\mathrm{Al}$. The results indicate that, before the formation of hydrogarnet, the more thermodynamically stable phase 
in the $\mathrm{CaO}-\mathrm{A} 12 \mathrm{O} 3-\mathrm{H} 2 \mathrm{O}$ system at ambient condition, the higher hydrate Afm phase decomposes into a lower hydrate Afm phase, releasing water to the system.

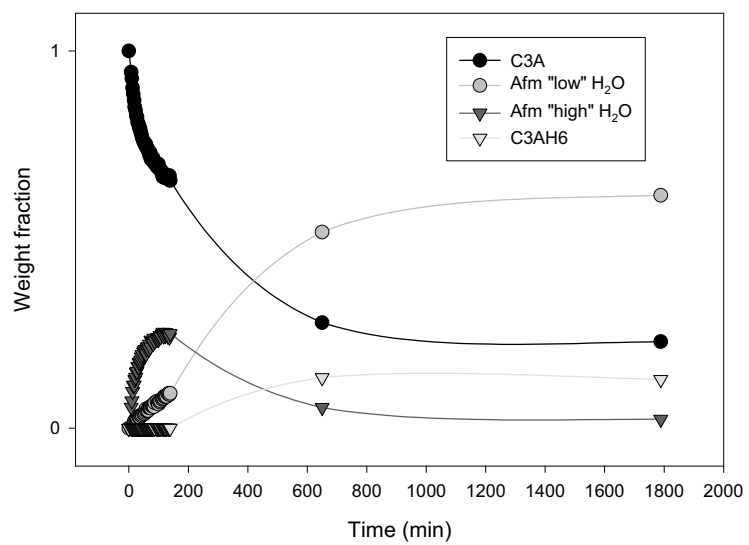

Figure 2. Phase evolution during the hydration of $C 3 A$.

The hydration of C4AF follows the same trend. The lattice parameters of Afm formed in ferric systems are $a=5.86$ and $c=21.38 \AA$. The $a$ value is sensibly larger than for Afm formed during the hydration of $\mathrm{C} 3 \mathrm{~A}$ - pointing out that $\mathrm{Fe}$ is easily incorporated in the Afm structure. Hydrogarnet structure is cubic and its lattice parameter is $12.575 \AA$ in $\mathrm{C} 3 \mathrm{~A}$ system and $12.661 \AA$ in $\mathrm{C} 4 \mathrm{AF}$ one. Considering that the $a$ axis in pure Fe-hydrogarnet has a value of $12.72 \AA$, and assuming a linear variation of cell parameter with composition, the hydrogarnet formed during $\mathrm{C} 4 \mathrm{AF}$ hydration incorporate almost all the iron available in the system.

\section{The hydration of Portland cement}

\section{Ettringite}

Ettringite, also called Aft-type phase, C3A. $3 \mathrm{CaSO}_{4} \cdot 32 \mathrm{H}_{2} \mathrm{O}$, is trigonal (space group $P 3{ }_{1} c$ ) and the crystal structure is composed of columns of alternately $\mathrm{Ca}-(\mathrm{O}, \mathrm{OH})$ and $\mathrm{Al}-(\mathrm{O}, \mathrm{OH})$ octahedra along the $c$ direction [1]. The columns are connected by $\mathrm{SO}_{4}$ groups and water molecules located in fairly large channels running parallel to the columns. Ettringite give rise to the reaction of $\mathrm{C} 3 \mathrm{~A}$ and $\mathrm{C} 4 \mathrm{AF}$ with sulphates and water. Ettringite is present in the first hours of $\mathrm{PC}$ hydration indicating that $\mathrm{C} 3 \mathrm{~A}$ and $\mathrm{C} 4 \mathrm{AF}(\mathrm{Ca} 2 \mathrm{AlFeO})$ are the most reactive phases in the early stages of the hydration process [1]. In figure 3 the phase evolutions in cement during the first hours of hydration are reported. In the first 3 hours the hydrous phase crystallised is ettringite. Gypsum is progressively consumed by reaction (3) and the amount of $\mathrm{C} 3 \mathrm{~S}$ is rather constant. During this period, the most relevant feature is the lattice parameter variation of ettringite (figure 4). The $a$ axis increases and the $c$ axis decreases. The structural features responsible for this behaviour are still not completely clear, however this trend was observed in all the cement systems investigated. It was also observed in ettringite crystallising from pure $\mathrm{C} 3 \mathrm{~A}$ and it is also mentioned in [3]. It seems to be directly related to $\mathrm{pH}$ 
condition and it could be due to the water and sulphate groups present in the columns of the ettringite structure.

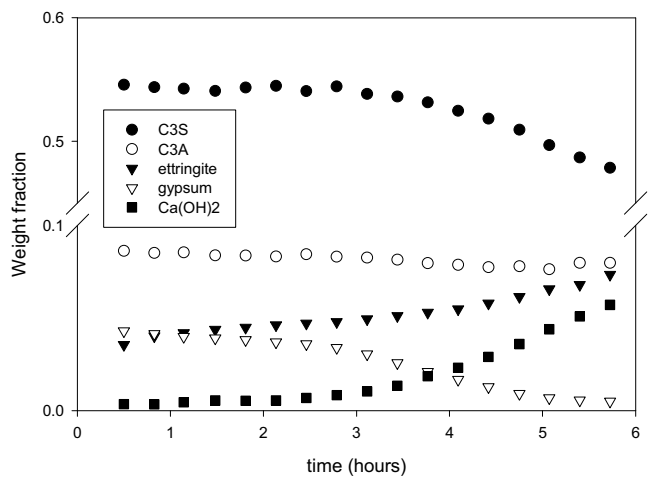

Figure 3. Phase evolution during the hydration of $P C$.
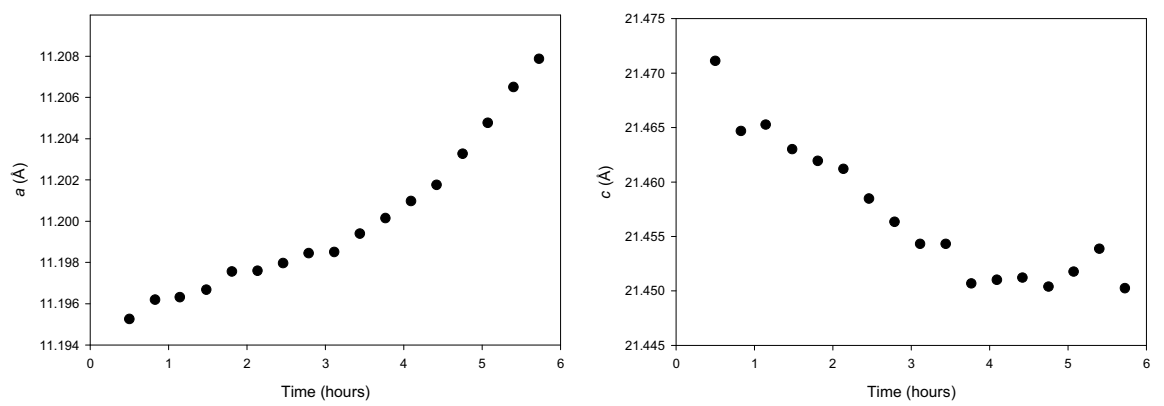

Figure 4. $a$ and c lattice parameter values of ettringite crystallised during the hydration of $P C$. The errors are not shown, since they have the same size of the symbols.

\section{CSH and portlandite}

After 3-4 hours the set of cement is finished and the C3S hydration starts, as described by reaction (4). The $\mathrm{CSH}$ is amorphous, but if the hydration is carried out in presence of at least $30 \%$ water and the XRPD experiments are performed in closed cells, avoiding water evaporation, $\mathrm{CSH}$ reveals a broad diffraction peak at low angle (figure 5). The d-spacing of the peak is a function of temperature and total water content. For example the data reported in figure 5 refer to a cement paste hydrated with $40 \%$ water at $25{ }^{\circ} \mathrm{C}$ and the d-spacing is about $35 \AA$. The formation of $\mathrm{CSH}$ is coupled with precipitation of $\mathrm{Ca}(\mathrm{OH}) 2$. High-resolution XRPD data have shown an interesting feature of portlandite. In figure 6 it is shown the splitting of the basal peak (001). The (100) diffraction (figure 6b) does not reveal any peak splitting. A possible explanation could be the presence of two different $\mathrm{Ca}(\mathrm{OH}) 2$ phases in the sample, precipitated from the pore solution and finely intercalated in the CSH structure. 


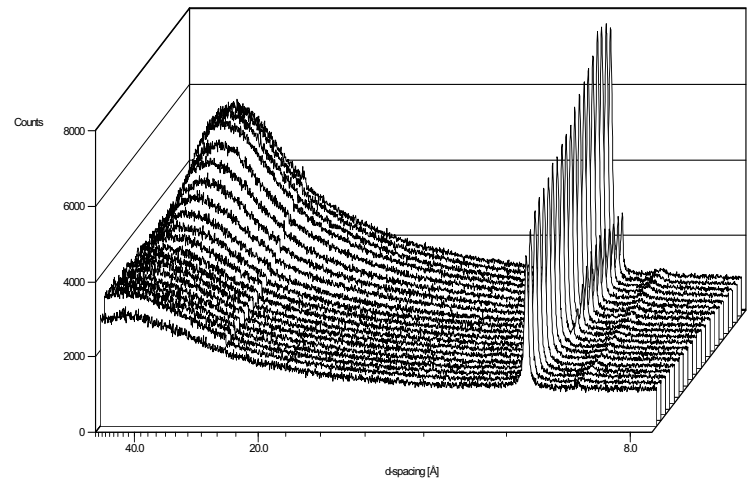

Figure 5. The broad peak centered at about $35 \mathrm{~A}$ is related to CSH. The data refer to the first 6 hours of hydration of PC. Each scan is collected over a 15 minutes period and the first scan in the figure was collected after 30 min from the beginning of hydration. In the figure the peak of ettringite is also visible at about $10 \AA$. The shoulder appearing from about 3 hours can be related to the formation of monosulphate.
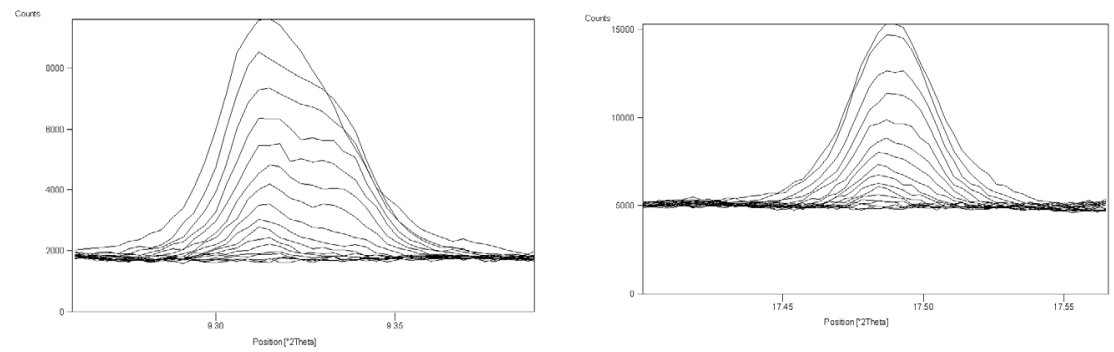

$a$

$b$

Figure 6. The 001 peak (figure 6a) and 100 peak (figure 6b) of portlandite, $\mathrm{Ca}(\mathrm{OH})_{2}$, in $\mathrm{PC}$. The data were collected with high resolution synchrotron XRPD.

\section{References}

1. Taylor, H.F.W., 1997, Cement Chemistry - 2nd Edition, (London: Thomas Telford Publishing).

2. Hewlett, P., 1998, Lea's Chemistry of Cement and Concrete, 4th Edition, (Arnold Publisher).

3. Bensted, J. \& Barnes, P., 2002, Structure and performances of concrete, (London: Spon Press)

4. Meneghini, C., Artioli, G., Norby, P., Balerna, A., Gualtieri, A. \& Mobilio, S., 2001, Translating Image plate system for in-situ experiments at GILDA beamline, J. of Synchr. Rad., 8, 1162-1166.

5. Larson, A.C. \& Von Dreele, R.B., 1994, General Structure Analysis System (GSAS), Los Alamos National Laboratory Report LAUR 86-748.

Acknowledgements. ESRF is acknowledged for the provision of beam-time. BM08 and BM16 staffs, John Wright in particular, are acknowledged for experimental assistance. 